\title{
Optimized Design for Electric Vehicle Quick Charging System in Consideration of Economic Feasibility
}

\author{
Young-Choon $\mathrm{Kim}^{1}$ and Moon-Taek $\mathrm{Cho}^{2}$ \\ ${ }^{1}$ Div. of Mechanical and Automotive Engineering College of Engineering, Kongju \\ National University, \\ ${ }^{2}$ Dept. of Electrical \& Electric Engineering, Daewon University College \\ 1yckim59@kongju.ac.kr, ${ }^{2} m t c h o @ m a i l . d a e w o n . a c . k r$
}

\begin{abstract}
This study simultaneously realized fast charger and low charger for electric vehicles by designing the driving power supply for the synchronization and interface of the battery system and power converter equipment of electric vehicles. In addition, it allowed the power of the output voltage and current to be supplied at a rate that is freely determined by user's setting regardless of the type of battery and power source, and also the charge and discharge devices for electric vehicles were developed using DSP. Furthermore, multi-step charging and discharging functions according to the changes in C-rate and CC (Constant Current) and $C V$ (Constant Voltage) charging functions were realized in which the system can stably and continuously be operated with efficiency of $95 \%$ or above.

Through such technological development, it has become possible to freely adjust the input voltage and output voltage according to the load condition through which production cost can be reduced and it is expected that it could be utilized in controller businesses for establishment of emergency power supply in the fields of multiple power supply apparatus of next generation electric vehicles and alternative energy that are leading the future green growth.

In the future, this can be utilized in On Board Charger and Off Board Charger of EREV (Electric Range Extender Vehicle) in addition to being possible to be used in development of SMPS for power supply of high capacity power converter. It seems that it can be manufactured as product through design of DC/AC converter for next generation electric vehicles.
\end{abstract}

Keywords: Fast charger, low charger, electric vehicle, DSP, CCCV

\section{Introduction}

According to the progress in commercialization with size reduction, weight reduction and increased efficiency in power conversion technology fields such as SMPS (Switching Mode Power Supply) and inverter technology that has become a trend since the late 1980s following the technological development in semiconductors, high precision control has not become possible as the drive circuit has become simpler and control technology has become more delicate through the recent commercialization of high power semiconductors (Power MSFET, IGBT, IPM, etc.) and technological progress in microprocessors and LSI (Large Scale Integration). Moreover, the importance of power conversion technology for high functionality, low power 
consumption and highly efficient operation among others is being emphasized due to the increased interest in energy saving becoming of high oil prices and more [1-2].

The electric vehicles were perceived to be zero emission vehicles in the late 1980s and their development has rapidly been pushed by having the possibility of being mass produced with novel technology in batteries in the early 1990s. At the same time, as various automotive systems that are operated by being connected to the engine changed to being electrical systems, the possibility of their independent application in vehicles has led to the development of the electric vehicles. Also, the development of electric vehicles has taken a serious roll as the Californian government (CARB) passed the ZEV (Zero Emission Vehicle) regulation in 1998 that obliges the use of electric vehicles. Many still agree that the electric vehicles are the solution for air pollution due to automotive emission and it is expected that the endeavor in their development will continue [3-5].

For the controllers that are currently applied in hybrid cars, the engine is only started when the engine efficiency is at its best excluding times when the charge amount of the secondary cell battery is insufficient, and it is only operated in conditions of maximum efficiency. During oscillation and light load, the power is received from the secondary cell battery and it is driven by motor only. When much torque is needed for cases such as rapid acceleration, overtaking and inclination, the vehicle is driven by utilizing all of the engine power, engine generator motor and secondary cell battery motor system. Such works are handled by the control system and the role of the control unit has now been increased as the artificial intelligence function, convenient apparatus and safety features apparatus are also applied. [6]

The automotive inverter includes the inverter and DC/DC converter and also possesses the water cooling system and cooling system. The inverter converts direct current (DC) and the DC/DC converter has the function of performing step down of high voltage of the input source to $12[\mathrm{~V}]$. Among the major parts, the IGBT (Insulated Gate Bipolar Transistor) switching device can be reduced in size by $20 \%$ or above with lower exothermic characteristic and higher efficiency compared to the pre-existing devices depending on its modification and improvement. It is expected that the type of charger that is appropriate for the new batteries in electric vehicles would make use of the pre-existing charging method by partially modifying it. Because the control unit, DC/DC converter and battery charger are being developed as a module package, it seems that the future electric vehicle market will also be developed in such trend.

Although the MOSFET driver design and high efficiency control after packaging design have significantly progressed due to the technological development in semiconductors, their base expansion or commercialization is quite being delayed due to realistic problems such as power switching and noise.

Subsequently, battery charging system that is possible to output free voltage of DC $12 \sim 300[\mathrm{~V}]$ by varying the voltage at the current output including the lead storage battery $48[\mathrm{~V}]$ for driving neighborhood electronic vehicles, $72[\mathrm{~V}]$ battery power and lithium polymer battery $42[\mathrm{~V}]$ and others has been developed in this study. In addition for battery charging and discharging, it was given a module through which the battery can be charged and discharged by fast acting to load changes by having an operation part to automatically control by perceiving changes in each mode during battery charging and discharging through usage of MC56F8345, which is a DSP controller.

This system supplies voltage and electric current according to the battery type and properties from lithium-ion to lead storage batteries through control of the PWM (Pulse Width Modulation) duty cycle even if the battery voltage is incorrect. Also, it is possible to adjust the charging current of different steps according to the load. Furthermore, in case of low charger, the voltage of electric vehicle was designed to be $2[\mathrm{kVA}]$ in consideration of DC 
output voltage being 310[V] upon application of AC voltage by having plug-in type. At the same time, in case of rapid charger, the capacity was designed to be $10[\mathrm{kVA}]$ in consideration of the electric current applied to the battery being approximately $35[\mathrm{~A}]$ by setting 1 [C-rate] as $3[\mathrm{~A}]$ so that adjustment of charging and discharging mode conversion of at least 10 steps would be possible.

\section{Design of EV Charger}

\subsection{DSP controller}

Microcontroller of 16 bit integer DSP of DSP56800E series of free scale that has been developed exclusively for controlling the motor was used as the controller of power converter for configuring the EV charger. In inside of the chip of 56F8322 has PWM block that can drive the power converter. For the hardware related to external interface, the voltage and current detect circuit, gate driver of PWM output, CAN circuit and input switches among others were designed according to the A/D input conditions, and the download circuit through JTAG port was configured.

The power converter for configuration of EV charger was designed in 2 types, which are MOSFET and IGBT.

In consideration of the production cost and that the battery charging voltage is low voltage, MOSFET was developed for neighborhood low speed vehicle. It was designed with IGBT in consideration of the plug in method and the charging voltage of HEV, EV and EREV being $300[\mathrm{~V}]$ or above. PWM output drives each of the MOSFET and gate circuit of MOSFET.

\subsection{Design of power converter}

The power converter is composed of step down chopper. The step down chopper has the function of controlling the energy that is transferred from the switch input to the output area while the inductor and capacitor act as the media for energy transfer or play the role of filter for removing the unnecessary ripple component in output voltage.

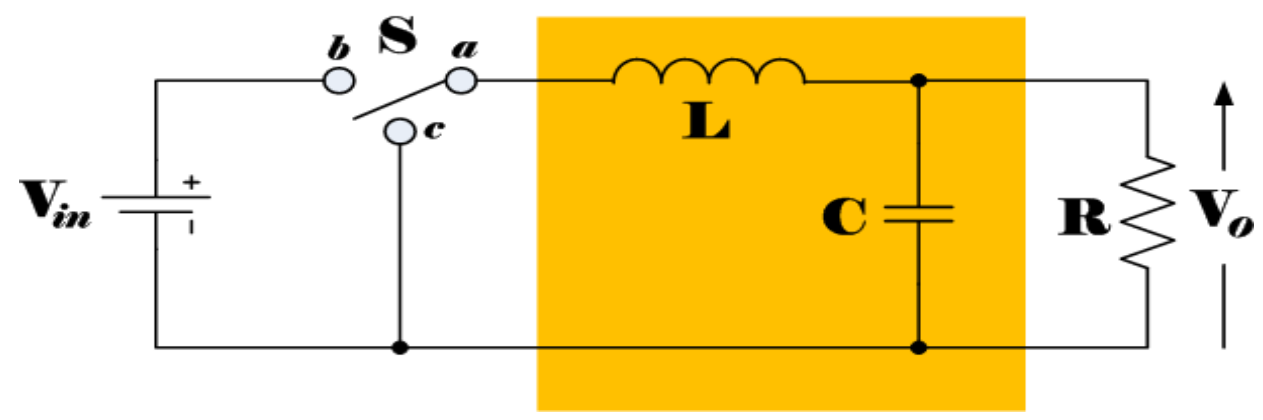

Figure 1. Step down chopper circuit

Although AC component of square wave aside from the DC component is included in the output voltage of step down chopper, it is constant DC source that is needed during load condition. Therefore, unnecessary AC component that is included in the output voltage must be removed. In order to remove such AC component, low pass filter circuit must be added as shown in Figure 1 in order to pass the DC component while cutting off the AC component. Also, if the inductor $\mathrm{L}$ and capacitor $\mathrm{C}$ are ideally very large, constant current would flow in inductor $\mathrm{L}$ and constant voltage would be applied on both ends of capacitor C. However in 
reality, the inductor and capacitor are not ideal and so there is ripple component included in the inductor current and capacitor voltage.

The ripple component in DC current or voltage is in most cases unnecessary components that become factors for reducing performance of power source. Therefore, when the ripple component of the output voltage is mostly removed by the LC filter circuit, the inductor current increases during the gate on time interval (DT). The ripple component of the maximum and minimum electric currents within the rise interval can be calculated by Equations (1) and (2). When the ripple fraction of the output voltage is calculated by considering the duty cycle D and the designed values L and C, Equation (3) can be expressed.

$$
\begin{aligned}
& I_{\max }-I_{\min }=\frac{V_{I N}-V_{\text {OUT }}}{L}=D T \\
& I_{\max }-I_{\min }=\frac{V_{I N}}{L}(1-D) T \\
& \Delta V_{\text {OUT }}=\frac{1}{L C} \frac{V_{I N}(1-D) D T^{2}}{8}
\end{aligned}
$$

Figure 2 shows the proposed step down chopper circuit. This circuit uses transformer that is secondary circuit AC 40[V] after application of AC 220[V] source in addition to using low voltage 60[V], high current 76[A] IXFH-76 NO7-11 MOSFET device. Moreover, 20 electrolytic condensers of $2000[\mu \mathrm{F}] / 63[\mathrm{~V}]$ were used to filter the maximum voltage of through single full wave rectification of the AC voltage in source. For the output, the load $100 \times \sqrt{2}$ was the battery, which operates through the voltage source and does not need a capacitor, and so the S/W program was used to allow it to operate in CC (Constant Current) mode. On the other hand, iron core was used for the inductor and in order to have the load stably maintain the desired electric current of $15[\mathrm{~A}]$, current constant reactor $1[\mathrm{mH}]$ was applied.

Figure 3 shows the ORCAD/PSPICE simulation circuit while Figure 4 shows simulation results of the electric current that flows through the reactance, input current, electric current that flows through the freewheeling diode, voltage on both ends of the reactance and voltage and current applied on the capacitor. Figure 5 shows the test mode.

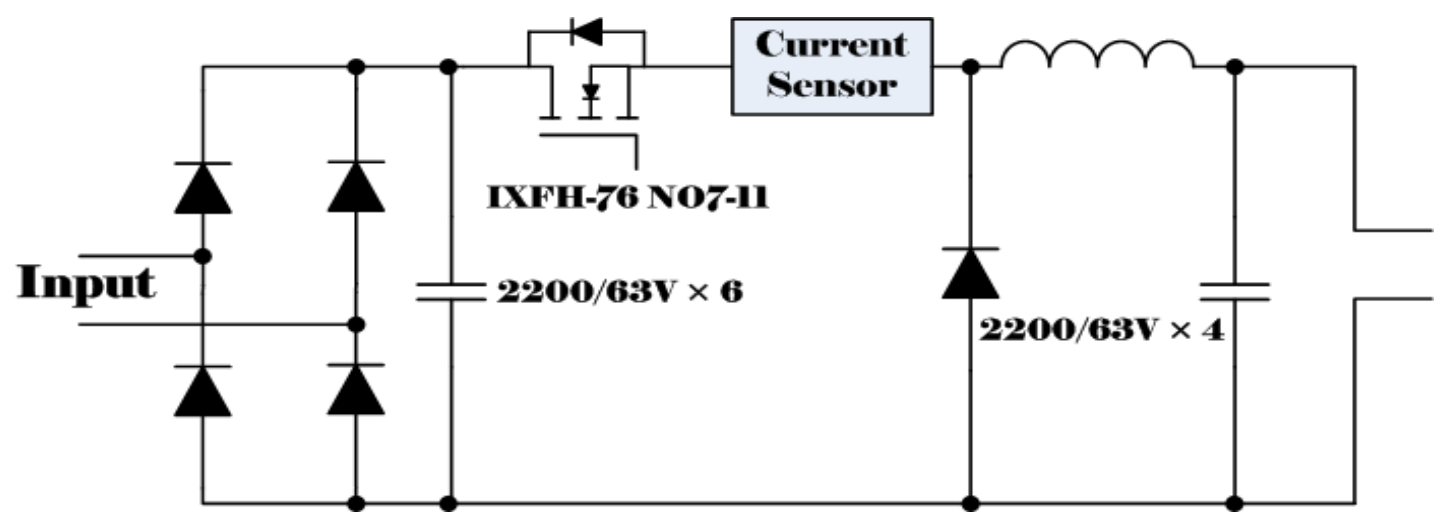

Figure 2. Proposed step down chopper 


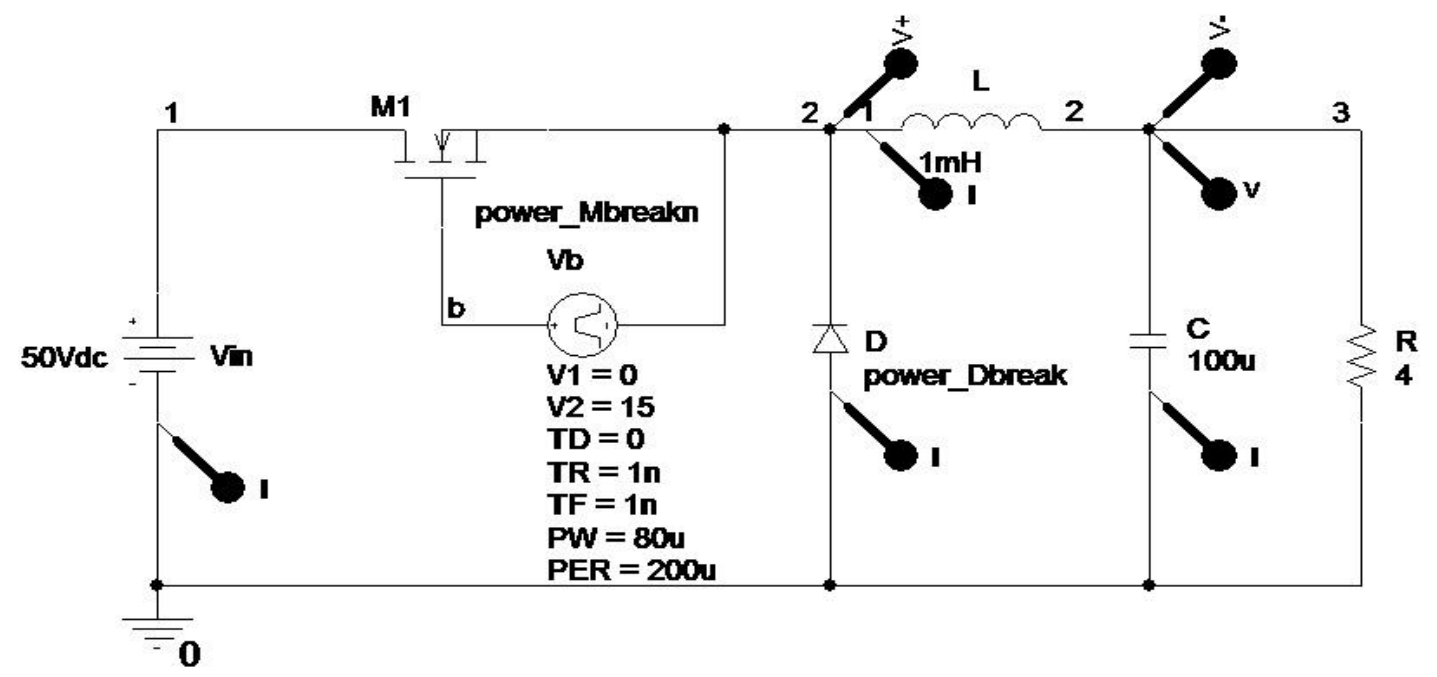

Figure 3. Simulation circuit diagram for the proposed circuit
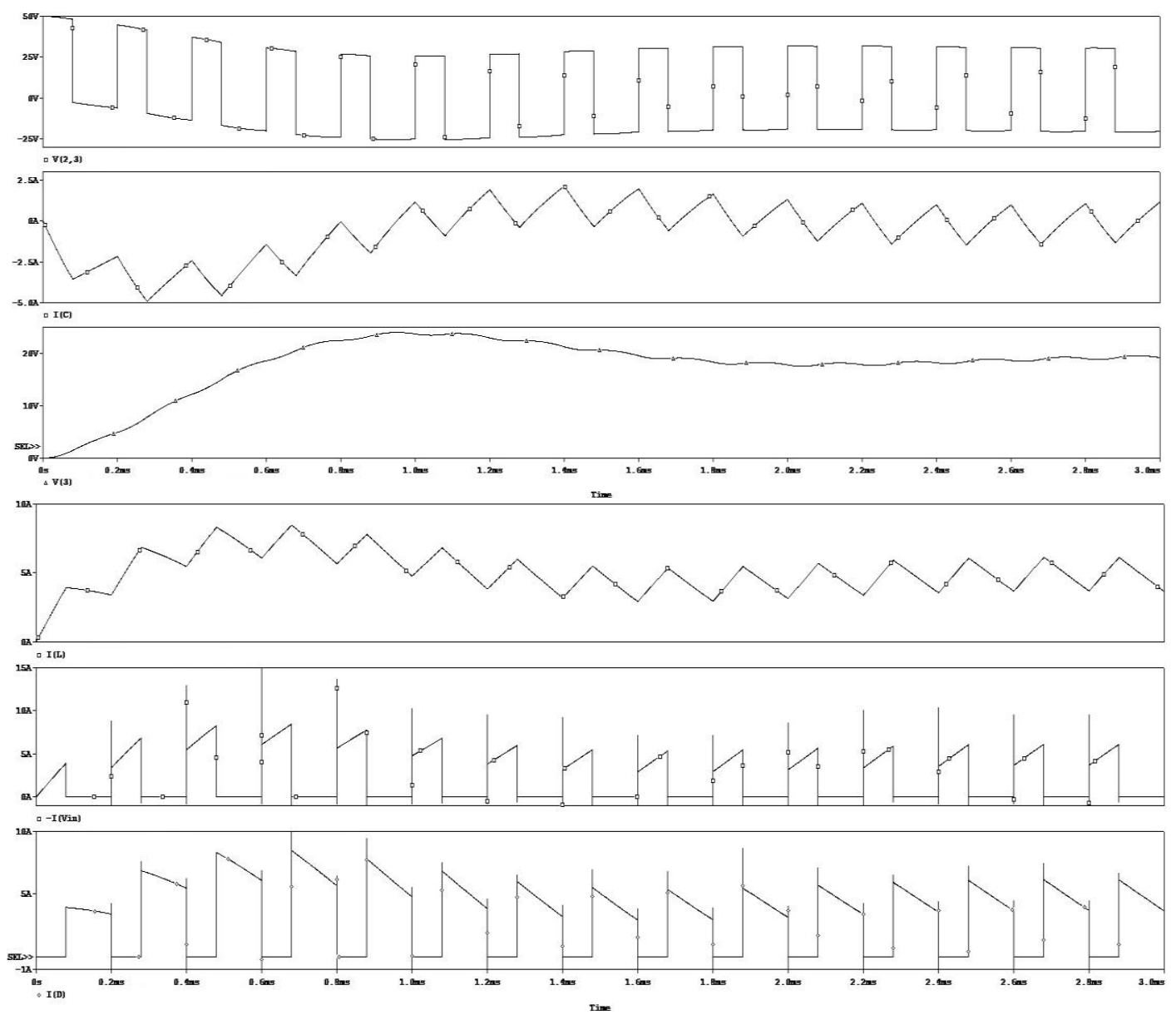

Figure 4. Simulation results of the proposed circuit 


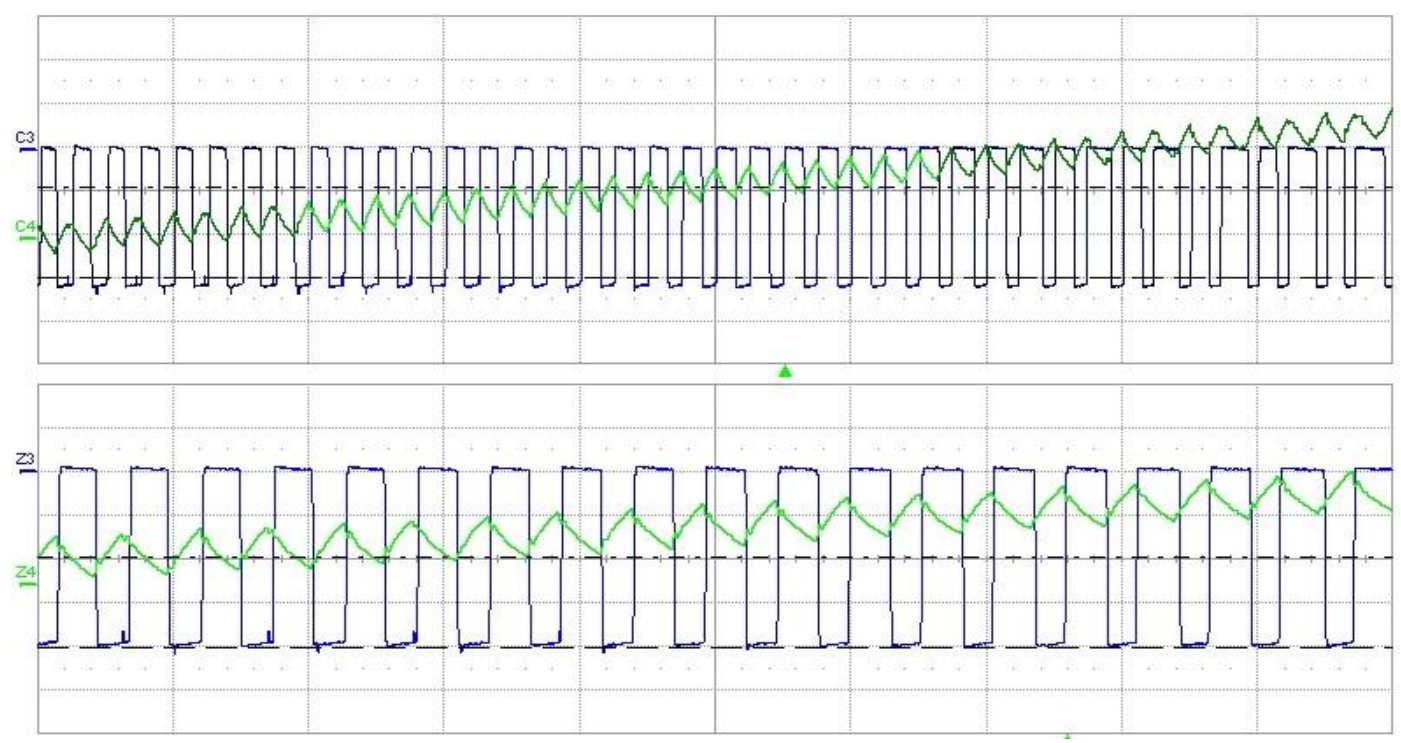

Figure 5. Test mode of the proposed circuit

\subsection{Controller design}

The step down chopper proposed in this study is $10[\mathrm{~kW}]$ with the power unit having switching frequency of $15[\mathrm{kHz}]$ and being driven under continuous mode at load of $10[\%]$ or above. The ripple of the output voltage was made to be $1[\%]$ or below. Also, the power convertor was made to operate stably even at wide range of load changes

The switching frequency was set to be $15[\mathrm{kHz}]$ in consideration of temperature restrictive conditions due to switching loss at IGBT. Because detailed prerequisite conditions of power converters have wide range of predictive changes of load conditions, requirements of transient response were not included. However, it must be considered in general that the transient response has short rise time and settling time with small or no overshoot voltage. This is why the appropriate value for rise time must be within 2[\%] with settling time and maximum percentage overshoot being within $t_{r} \leq 1[\mathrm{~ms}], t_{s} \leq 5[\mathrm{~ms}], M_{p} \leq 5[\%]$.

In order to supply stable power source to the load, the step down chopper must stably maintain the DC link voltage within short time even under load disturbances. Therefore, feed forward compensator was used in this study in order to prevent excessive variation in load current from hindering the controller performance of the step down chopper. Such feed forward compensator compensates the steady state output error that occurs due to large step changes in the converter's input reference signal, improves the dynamic characteristics and also reduces the disturbances that are present in the converter output. Such feed forward compensator does not affect the system stableness and has the advantage of being easy to be configured. The feed forward compensation loop is configured by being inserted in the voltage controller output and the voltage control is allowed to flow, which minimizes the effects of load variation and improves the transient response and steady state response.

Equation (4) shows the voltage controller including the feed forward compensator and Figure 6 shows the control block diagram. Here, $k_{f}$ refers to the feed forward compensator gain wherein the optimal value is determined through the frequency response characteristic of the output voltage with regards to the load current. 


$$
d(t)=k_{p}\left[v_{r e f}(t)-v_{0}(t)\right]+K \int_{i}\left[v_{r e f}(t)-v_{0}(t)\right] d t-k_{f} \frac{d i_{0}(t)}{d t}
$$

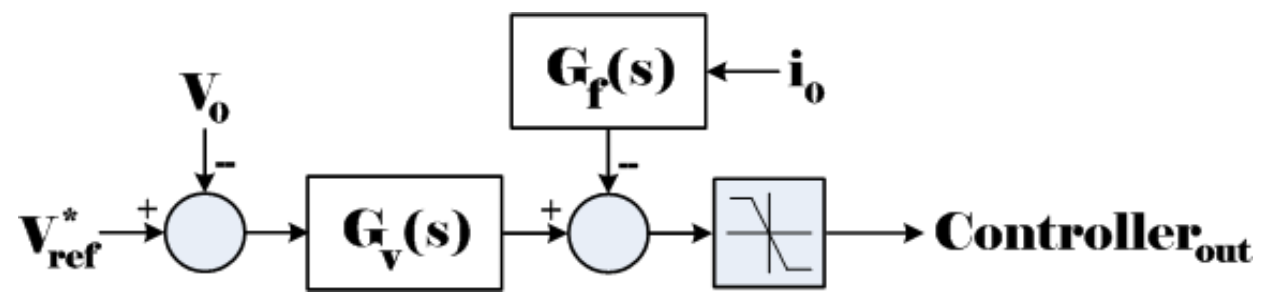

Figure 6. System control block diagram including the feed forward compensator

\section{Simulation Results}

The algorithm that uses the feed forward compensator proposed in this study was applied in the step down chopper. The purpose of the simulating this system was to understand the characteristics of the DC link voltage control of the DC power supply unit that is comprised of step down chopper of $10[\mathrm{~kW}]$. In order to analyze the general control properties, control block was configured by using the MATLAB/SIMULINK as shown in Figure 7.

For the system parameters, the output voltage was $300[\mathrm{~V}]$ when the input voltage was $400[\mathrm{~V}]$ with switching frequency of $15[\mathrm{kHz}]$ and reactance of $1[\mathrm{mH}]$.

For the test condition, load of $10[\%](16.36[\Omega])-100[\%](1.636[\Omega]-10[\%](16.36[\Omega])$ was applied.

When the load current feed forward compensator was applied in the simulation results of Figures 8 and 9, it can be observed that the transient characteristics and steady state characteristics of the output voltage improved significantly. Therefore, it can be understood that the properties belonging to the dynamic characteristics that are required by the system proposed in this study can be obtained.

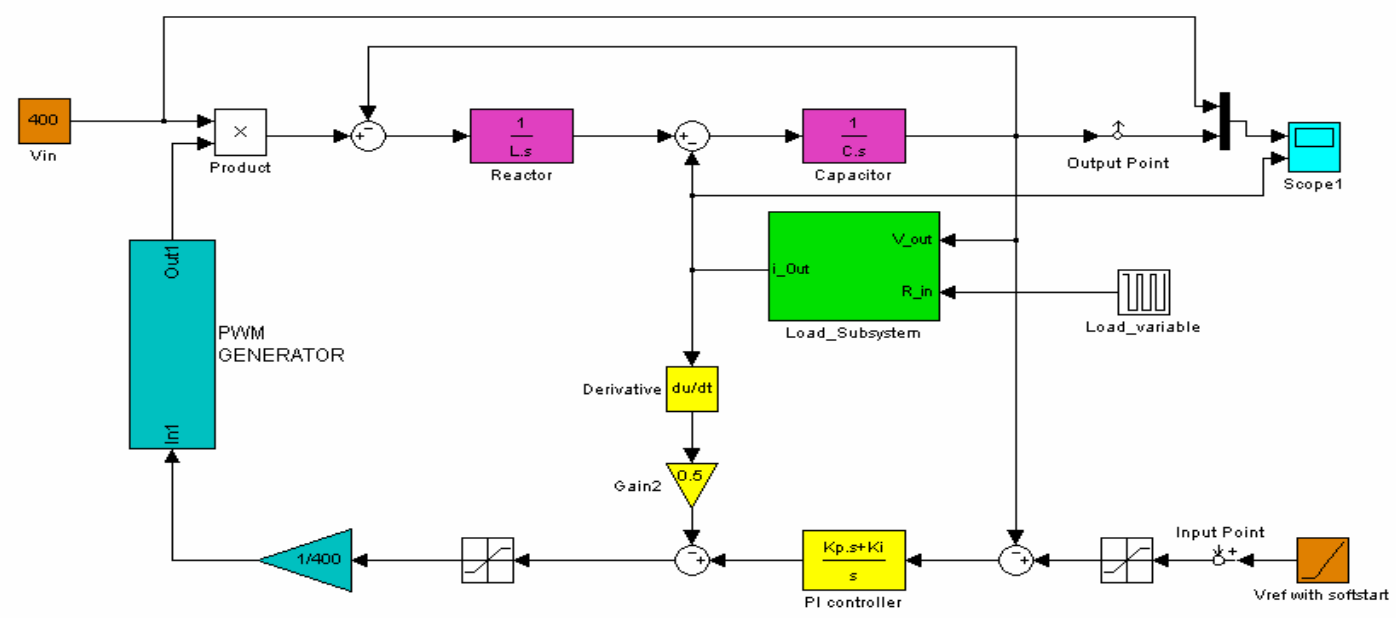

Figure 7. SIMULINK block diagram of step down chopper 

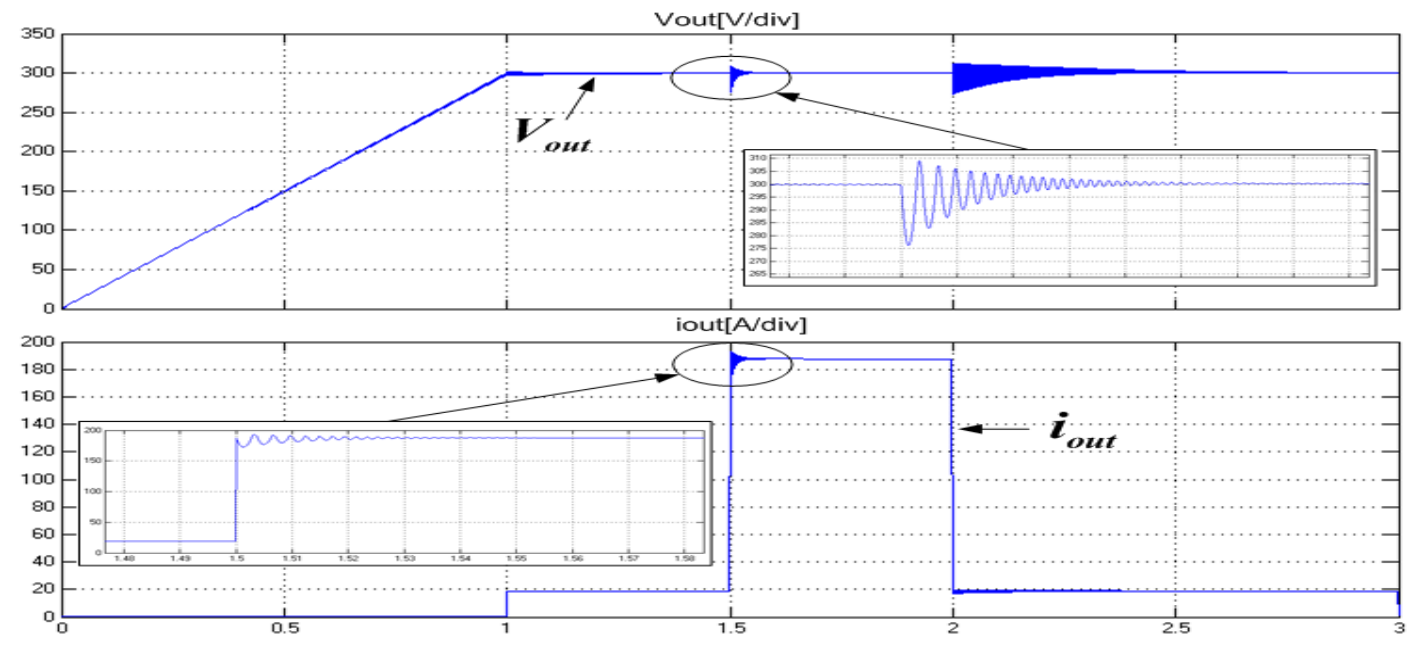

Figure 8. With application of PI controller only

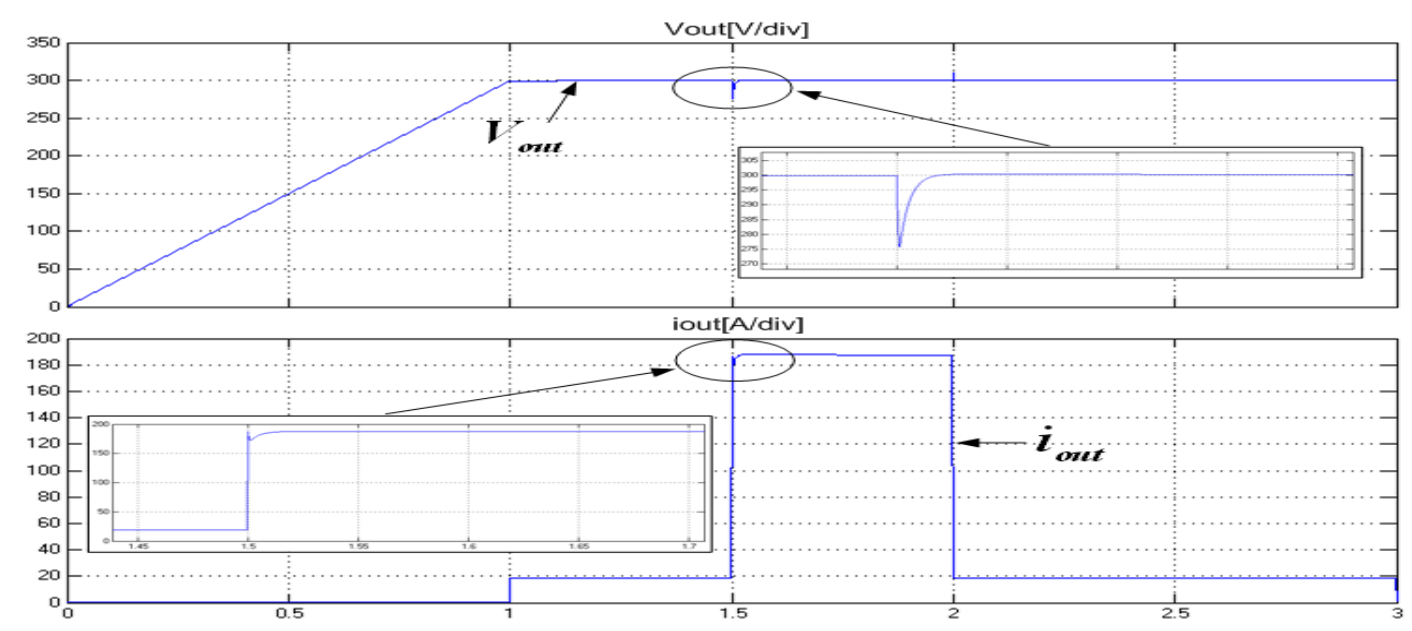

Figure 9. With application of load current feed forward compensator

\section{Test Results}

Figure 10 shows the output wave (above) between the IGBT emitter and base during PWM modulation and the voltage wave (below) that is inputted during battery charging. Figure 11 shows the voltage (above) and current (below) waves that are inputted during battery charging. Figure 12 shows the voltage and current waves that have been measured under the same conditions as in Figures 10 and 11 in order to measure the driving characteristics during the startup. Figure 13 shows the waves to observe the driving characteristics of the system from rapid charging to low charging by varying the load while driving. Figure 14 shows the waves to observe the driving characteristics of the system from low charging to rapid charging by varying the load while driving. (F1:10[kW] level drive, F2:5[kW] level drive.) Figure 15 shows the results of the load test that was conducted to check the safety characteristics of the system upon load change under the same conditions. The results of measuring its efficiency show 98.1[\%] efficiency as shown in the F3 display. 


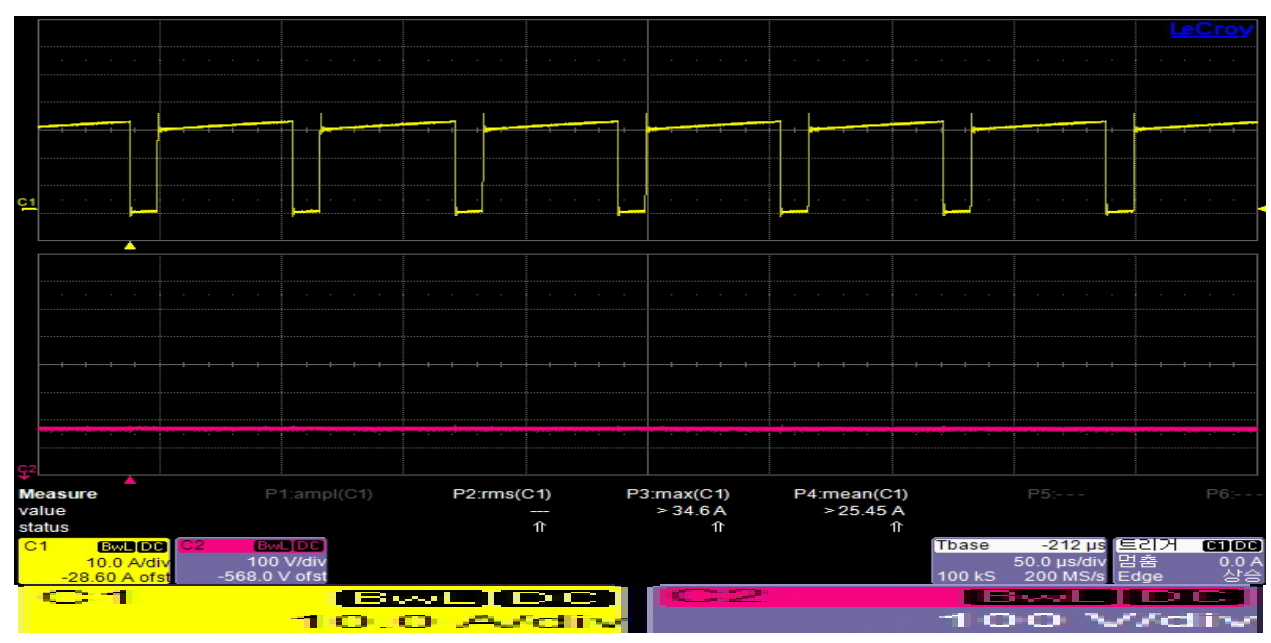

Figure 10. PWM modulation wave

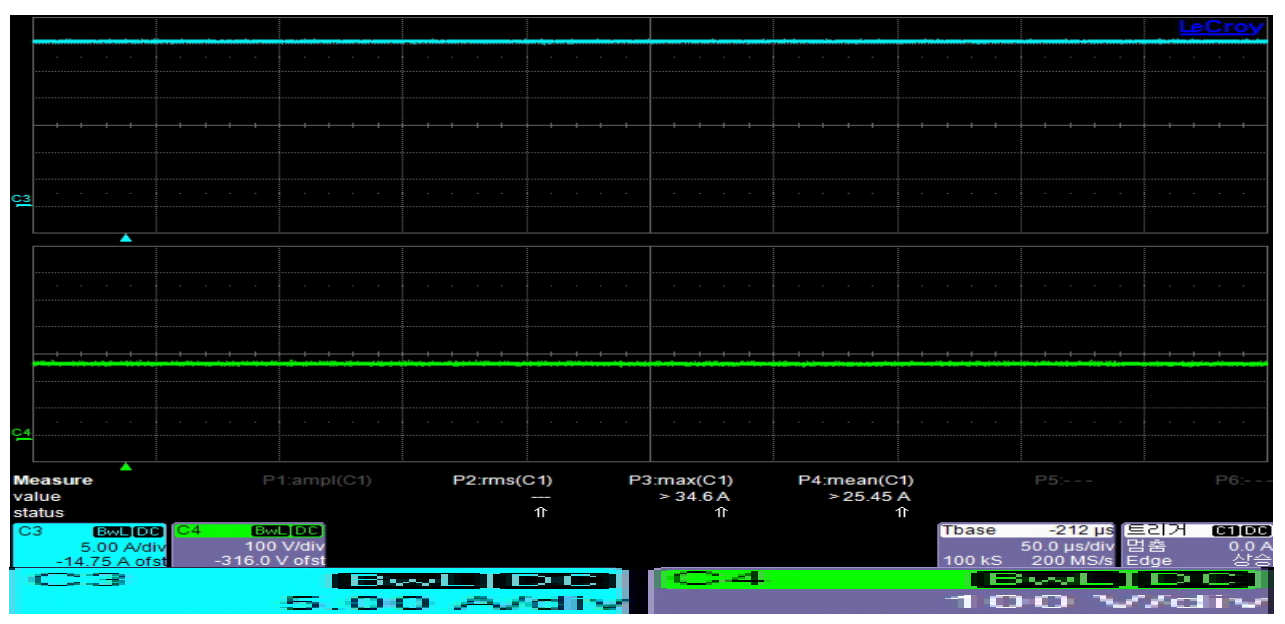

Figure 11. Voltage and current wave of output end during battery charging

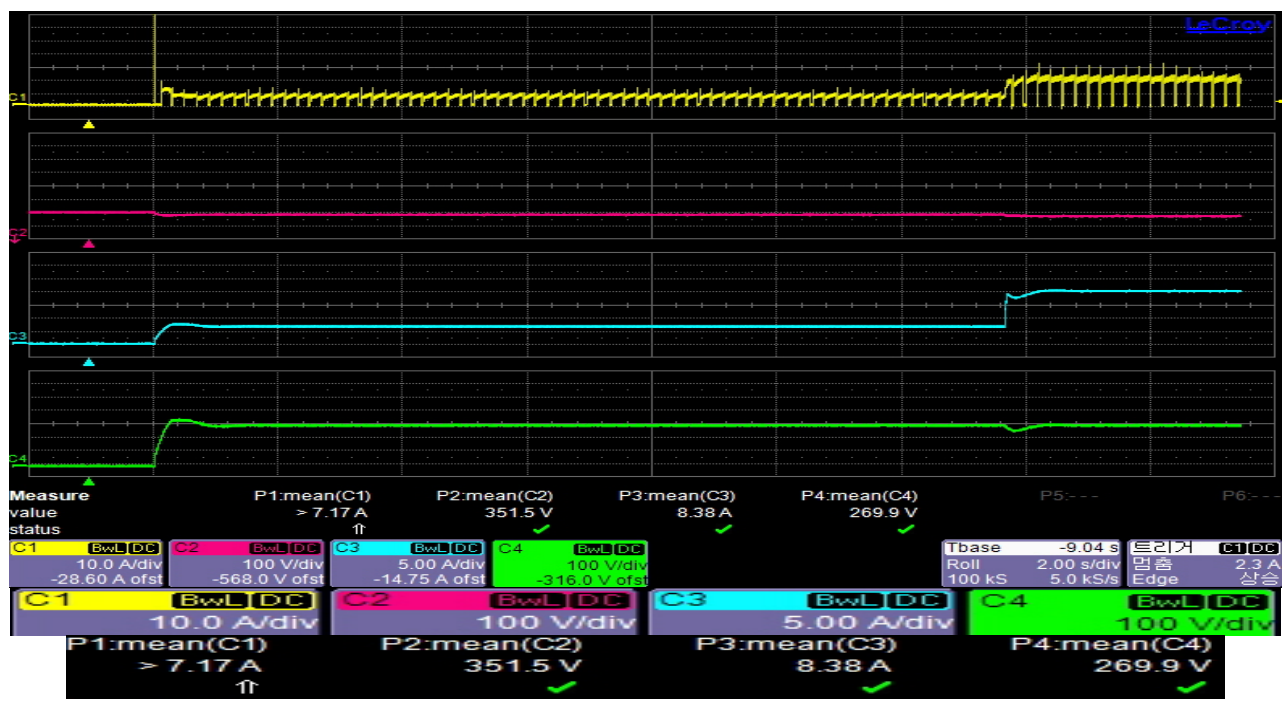

Figure 12. Voltage and current wave of input and output ends during load test 


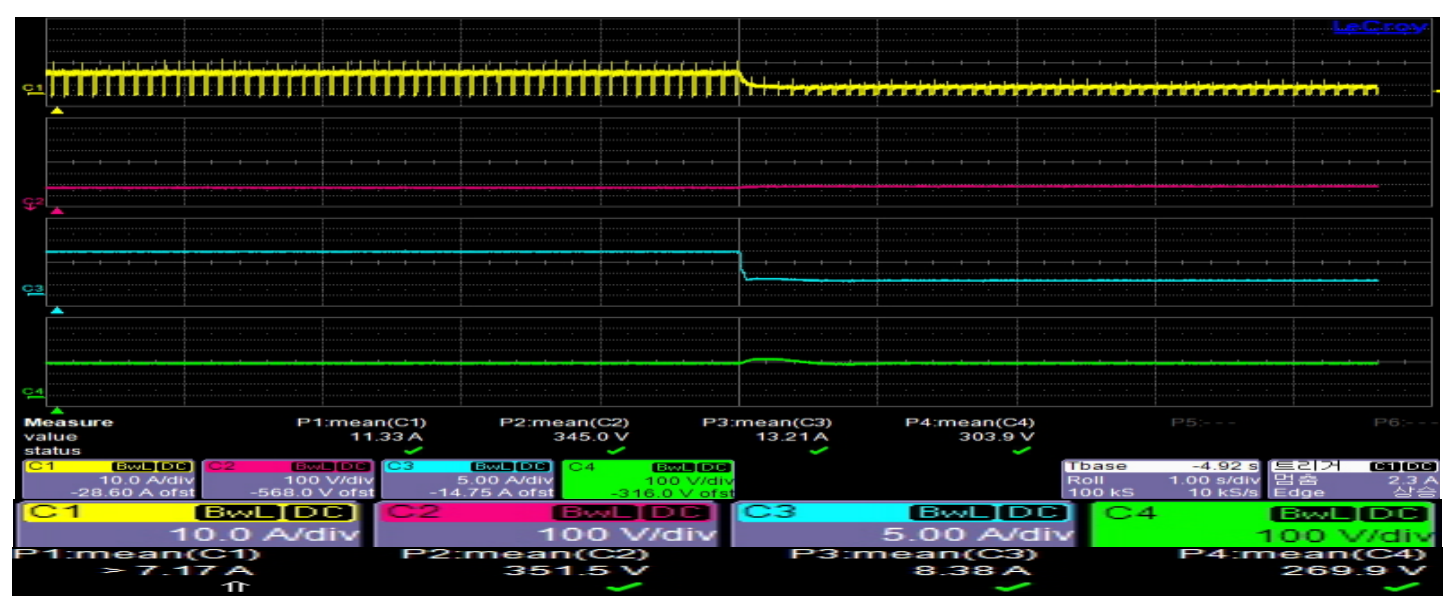

Figure 13. Voltage and current wave of input and output ends during load test

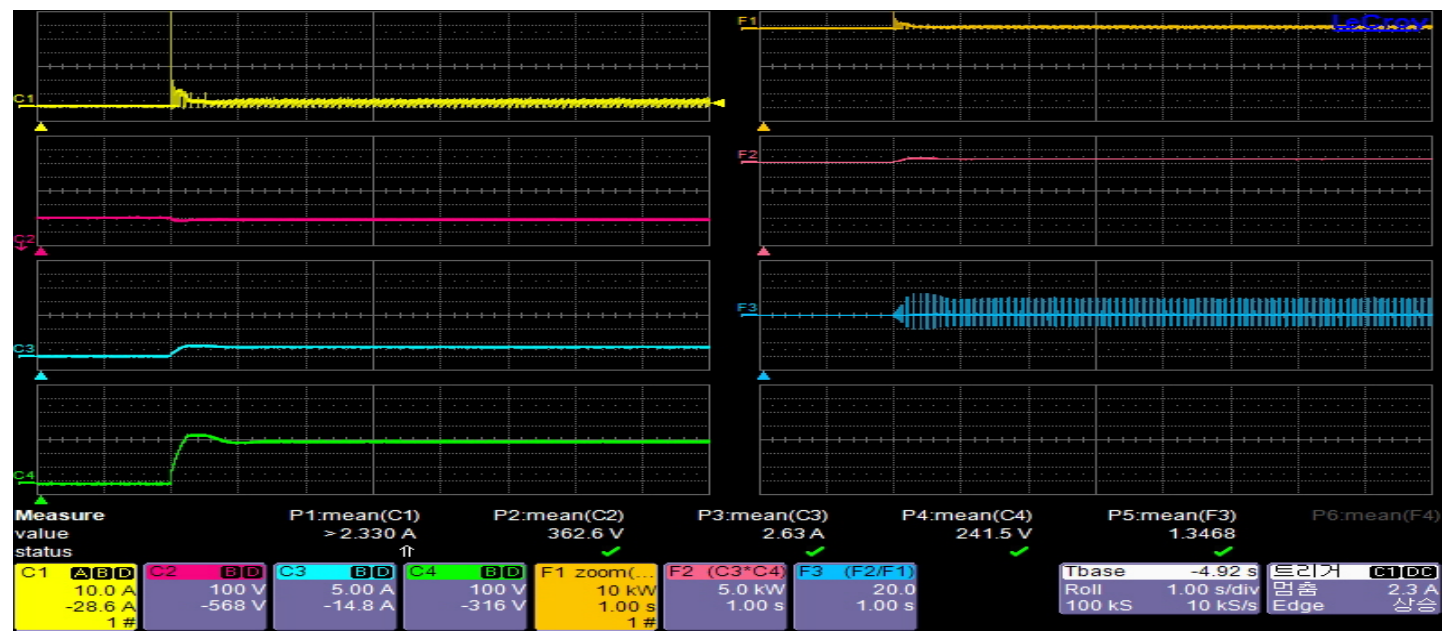

Figure 14. Voltage and current wave of input and output ends during load test

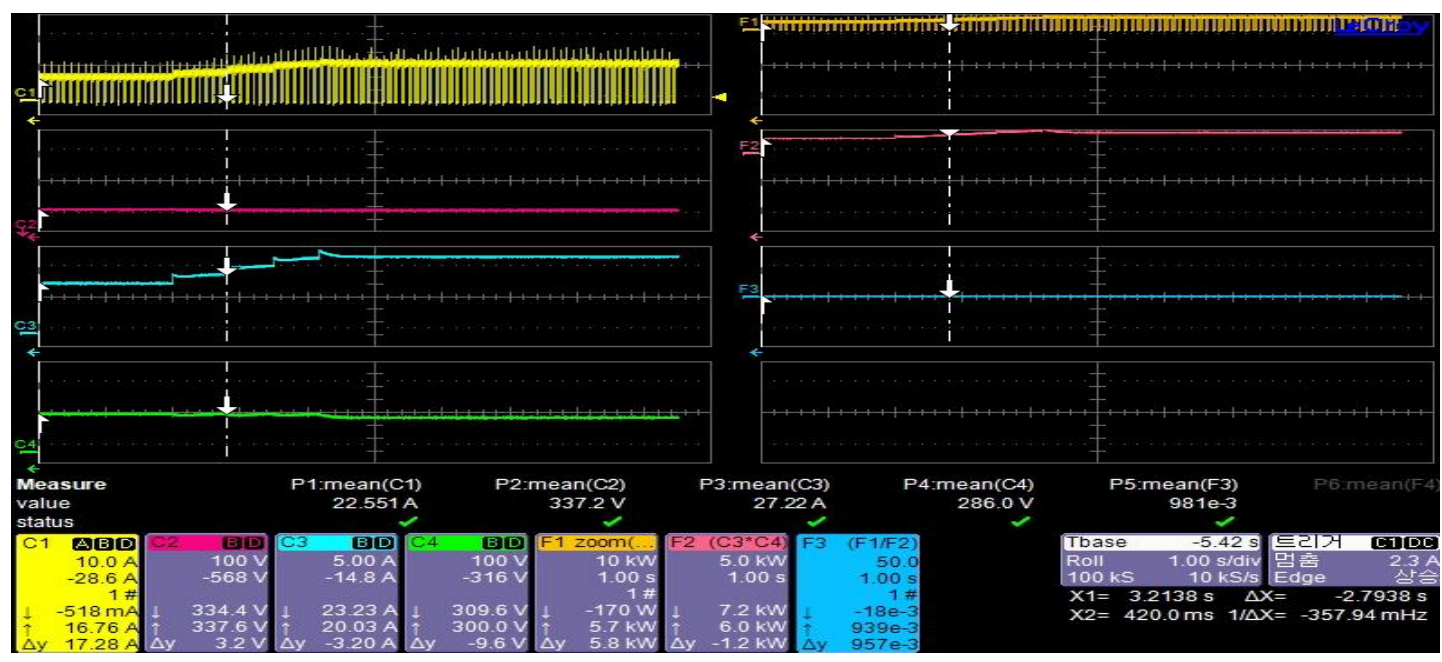

Figure 15. Voltage and current wave of input and output ends during load test/effiency measurement 


\section{Conclusion}

This study presents electric vehicle charger technology that can be charged and discharged regardless of not only low voltage or high voltage but also the type of battery by making use of high performance DSP. In addition, the input voltage and output voltage can freely be adjusted under load conditions and it is suggested that it can also be utilized as controller for set up of emergency power supply in the fields of multiple power supply apparatus in EV and alternative energy.

By comprehensively applying high voltage semiconductor device for MOSFET, which is a low voltage type, and IGBT for high voltage type, widely used rapid charging and low charging functions can both be used. Also, wide usage of the battery was made possible by using PWM buck converter that functions under CCCV (Constant Current Constant Voltage) mode. Also, continuous output even during trip was guaranteed by designing the controller to be fixed and yet variable according to the load characteristics. It was designed to allow easy $\mathrm{A} / \mathrm{S}$ by managing the battery type being used and charging and discharging. Moreover, drive power design technology for synchronization and interface of the power converter by applying the power supply unit in connection with the battery was made possible.

Finally, multi-step charging according to C-rate changes and CV (Constant Voltage) charging functions were realized with system that can continuously be operated with efficiency of $95 \%$ or above.

It is expected that it can be applied not only in Off Board Charger of electric vehicles but also On Board Charger of EREV (Electric Range Extender Vehicle) in the future.

\section{Acknowledgements}

This article is a revised and expanded version of a paper entitled Optimized Design for Electric Vehicle Quick Charging System presented at International Symposium on Advanced and Applied Convergence held on November 14-16, 2013 at Seoul, Korea.

\section{References}

[1] Y. -C. Kim and M. -T. Cho, "Optimized Design for Electric Vehicle Quick Charging System”, International Symposium on Advanced and Applied Convergence, (2013), pp. 201 204

[2] Y. -C. Kim, M. -T. Cho, Ho-Bin Song and Ok-Hwan Kim” ,Regeneration Break Control in the High-Speed Area using the Expending of the Constant Torque Region and Power Region" ,International Journal of Control and Automation, vol.6, no.4, August (2013), pp. 347 356

[3] Y. -C. Kim, H. -B. Song, M. -T. Cho, and S. -H. Moon, "A Study on Direct Vector Control System for Induction Motor Speed Control”, EMC Technology and Service, LNEE, vol. 181, (2011), pp. 599 612.

[4] Y. -C. Kim, H. -Bin Song, and M. -T., "A Study on the Improved Stability of Inverter through History Management of Semiconductor Elements for Power Supply" ASEA/DRBC 2012, CCIS 340, (2012), pp.155 162.

[5] Y. -C. Kim, H. -B. Song, M. -T. Cho, C. -S.Lee, O. -H. Kim and S. -Y. Park, "A Study on the Improved Stability of Inverter through History Management of Semiconductor Elements for Power Supply", (2012), GST 2012, CCIS 340, DOI: 10.1007/978-3-642-35267-6_20, pp. 155-162.

[6] Y. -C. Kim, H. -B. Song, M. -T. Cho and S. -H. Moon, "A Study on Vector Control System for Induction Motor Speed Control”, EMC 2012, DOI: 10.1007/978-94-007-5076-0_73, (2012), pp. 599-812.

[7] M. L. Yamagishi and T. Akagi, "Active-Power Control of Individual Converter Cells for a Battery Energy Storage System Based on a Multilevel Cascade PWM Converter", IEEE Transactions on Power Electronics, vol. 27, (2012), pp. 1099 1107.

[8] Z. Zhang, H. Xu, L. Shi, D. Li and Y. Han, "A unit power factor DC fast charger for electric vehicle charging station”, Power Electronics and Motion Control Conference (IPEMC), 2012 7th International, vol.1, (2012), pp.411-415. 


\section{Authors}

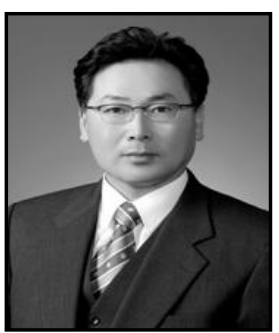

\section{Young-Choon Kim}

He was born in Korea on August 9, 1959. He received the ME.Eng. and Ph.D. degrees from MyongJi Univ. Korea in 1989 and 1997, respectively. Currently, he is an professor in the Kongju National Univ. Dept. of Mechanical \& Automotive Eng, Korea. His special field of interest includes power electric, electrical machine, new renewable energy, PSPICE, Matlab, Fatigue and Fracture Mechanics.

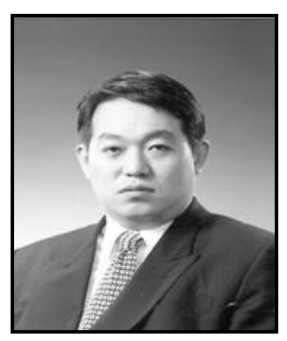

\section{Moon-Taek Cho}

He was born in Korea on February 23, 1965. He received the B.S., M.Eng. and Ph.D. degrees from MyongJi Univ. Korea in 1988, 1990 and 1999, respectively. Currently, he is an a professor in the Daewon Univ. College Division of Electrical \& Electronic Engineering, Korea. His special field of interest includes power electric, electrical machine, new renewable energy, super-capacitor, PSPICE, CASPOC. 